\title{
VARIEDADES LINGUÍSTICAS E USOS SOCIAIS DA COMUNIDADE DE FALA DOS "HOLANDESES" DE CARAMBEÍ/PR
}

Leticia Fraga ${ }^{1}$

leticiafraga@gmail.com

RESUMO: Carambeí, uma pequena cidade do Paraná, foi a primeira colônia holandesa fundada no Brasil, em 1911. Considerando-se que a população de Carambei é muito complexa cultural e linguisticamente, este estudo intenta fazer um levantamento do uso funcional do português e do holandês ali.

Nós concluimos que os grupos $1 \mathrm{M}$ e $1 \mathrm{~F}$ preferem o holandês; os grupos $2 \mathrm{M}$ e $2 \mathrm{~F}$ são bilingues em portugués e holandês; os grupos $3 \mathrm{M}$ e $3 \mathrm{~F}$ são monolingues em português.

Palavras-chave: lingua portuguesa; lingua holandesa; variedades linguísticas; usos sociais

\section{INTRODUÇĀO}

Carambeí, uma pequena cidade de dezessete mil habitantes, distante $15 \mathrm{~km}$ de Ponta Grossa, no Paraná, é uma das três colônias holandesas daquele estado. Mais especificamente, a primeira - portanto, a mais antiga - colônia holandesa do Brasil, fundada em 1911. 
Neste artigo, buscar-se-á caracterizar a comunidade de fala "holandesa" 2 de Carambei, uma tarefa bastante comple$\mathrm{xa}$, respondendo em linhas gerais às seguintes questões: "Quem fala que língua, onde, a quem e sobre o quê" (HYMES, 1964, p. 251)?

\section{Materiais E MÉTODOS}

Nesta pesquisa, para fazer o levantamento dos dados a respeito do processo de aquisição da língua portuguesa e da língua holandesa na comunidade "holandesa" de Carambeí, utilizou-se o método etnográfico, pois estudos etnográficos muito têm contribuído para o entendimento da história da cultura de diferentes povos, uma vez que possibilitam que "uma variedade de métodos seja utilizada para minimizar a imposição das percepções e categorias culturais [do pesquisador] no registro e interpretação de um outro sistema" como afirma Saville Troike (1989, p. 128). Portanto, utilizar o método etnográfico significa levantar todos os dados possiveis de uma comunidade, no sentido de investigar um determinado grupo e sua cultura específica. Segundo Arnould e Wallendorf (1994), o método etnográfico caracteriza-se pela prática de:

- Coleta de dados e registro das ações no seu local natural (ou seja, onde acontecem na realidade, e não em laboratórios ou em situações superficiais);

2 Neste trabalho, as designações "holandês(es)"/"holandesa(s)" (entre aspas) serão usadas para fazer referência ao individuo descendente de holandeses que nasceu no Brasil. em oposição às designações "brasileiro(s)" / "brasileira(s)" (também entre aspas), que se referem ao individuo que nasceu no Brasil e não é descendente de holandeses. A opção por estas designaçōes deu-se por duas razōes: os próprios "holandeses de Carambei fazem esta distinção (autodenominam-se "holandeses" e distinguem-se dos não holandeses, a quem chamam "brasileiros") e Rickli (2003) propōe em seu trabalho sobre a colônia de Castrolanda a utilizaçāo do termo "brasileiro" como referência ao individuo que nasceu no Brasil e que não tem ascendência holandesa. 
- Participação do pesquisador em um contexto cultural especifico;

- Incorporação de múltiplas fontes de dados, entre as quais se encontram a observação (que pode ser participante ou não participante) e a entrevista (não estruturada ou estruturada).

Assim, o método etnográfico requer que o investigador penetre no universo cultural de um grupo étnico específico e, guiado basicamente pelas informaçōes ai obtidas, desvende sua história, seus significados e suas respectivas inter-relações. Em etapa posterior, é preciso selecionar os eventos correlacionados aos objetivos investigativos propostos ou selecionar o que, no curso da investigação, se revele mais significativo para o específico interesse do etnógrafo. Por envolver a chamada observação participativa, os estudos etnográficos proporcionam uma ampla visão sobre, por exemplo, a real significação de determinados fatores sociais e linguisticos em determinada comunidade de fala. Logo, ao adotar um método dessa natureza, evitam-se, por exemplo, meras descrições.

Em sintese, atentou-se para uma questão inerente à tarefa do etnógrafo, a de suspender temporariamente o julgamento e abstrair os conhecimentos próprios, que são consequência do pertencimento a uma cultura particular, de forma a tentar entender outra vida cultural como um "insider" Esse foi o procedimento adotado quando da coleta de dados etnográficos no município de Carambei- PR.

A investigação da comunidade "holandesa" de Carambeí, mediante aplicação do método etnográfico e da etnografia da comunicação, compreendeu aproximadamente o período de um ano e meio: de março de 2005 a agosto de 2006. A observação como "sympathetic participant-observer" ou como "analytical participant-observer" isto é, junto com o grupo e sobre o grupo, foram ambas adotadas, já que a comunidade está relativamente acostumada a tais formas de observação, 
principalmente pelo contato com jornalistas, com turistas do pais e do exterior e com pesquisadores.

Os instrumentos de coleta de dados utilizados nessa pesquisa foram a observação, a entrevista e o questionário, que são bastante relevantes no caso de um trabalho de campo na área de sociolinguística, como é o caso deste estudo.

Os informantes selecionados para a entrevista residem tanto numa pequena área urbana - um pequeno centro onde se localizam agências bancárias, escola estadual, lojas, supermercados etc. - quanto em locais mais afastados, na área propriamente rural (em fazendas e sitios) e seu universo cultural foi igualmente investigado em ambas as localizações, uma vez que se visitaram várias familias "holandesas" de Carambeí. No total, entrevistaram-se vinte e quatro pessoas.

Os critérios gerais pré-estabelecidos para a seleção dos informantes foram os seguintes:

- Ter mais de 18 anos;

- Ser descendente de holandeses (pelo lado materno ou paterno);

- Ter nascido (ou ter-se mudado até os 5 anos) e ter sempre vivido na regiāo de Carambeí;

- Ser bilíngue em português/holandês em algum grau.

Antes de cada entrevista, justificávamos a realização do estudo, dizendo que pretendiamos compreender melhor a história da colonização holandesa de Carambeí. Na sequência, preenchiamos uma ficha com os dados pessoais dos informantes, tais como nome completo, idade, escolaridade, cidade em que moram, endereço etc. Na ficha havia também um espaço reservado para anotar o local em que a entrevista foi realizada e a data. Os informantes foram identificados pelas iniciais para preservar a identidade de cada um.

No quadro a seguir, pode-se observar o perfil dos informantes que forneceram os dados referentes à discussão so- 
bre os usos linguísticos da comunidade de fala dos "holandeses" de Carambei.

\begin{tabular}{|c|c|c|c|c|c|}
\hline Informante & Sexo & Idade & Ascendência & Naturalidade & Profissão \\
\hline $\mathrm{DG}$ & $\mathrm{M}$ & 70 anos & $\begin{array}{l}\text { filho de pais } \\
\text { holandeses }\end{array}$ & Carambei & aposentado \\
\hline $\mathrm{HS}$ & $M$ & 73 anos & $\begin{array}{l}\text { filho de pais } \\
\text { holandeses }\end{array}$ & Carambeí & agricultor \\
\hline $\mathrm{JG}$ & $M$ & 71 anos & $\begin{array}{l}\text { filho de pais } \\
\text { holandeses }\end{array}$ & Carambeí & pecuarista \\
\hline$\overline{B D}$ & $\bar{M}$ & 71 anos & $\begin{array}{l}\text { filho de pais } \\
\text { holandeses }\end{array}$ & Carambeí & agricultor \\
\hline JLG & $\bar{F}$ & 75 anos & $\begin{array}{l}\text { filha de pais } \\
\text { holandeses }\end{array}$ & Carambeí & dona de casa \\
\hline WGG & $F$ & 75 anos & $\begin{array}{l}\text { filha de pais } \\
\text { holandeses }\end{array}$ & Carambeí & dona de casa \\
\hline THS & $F$ & 72 anos & $\begin{array}{l}\text { filha de pais } \\
\text { holandeses }\end{array}$ & Carambeí & dona de casa \\
\hline WCGE & $F$ & 74 anos & $\begin{array}{l}\text { filha de pais } \\
\text { holandeses }\end{array}$ & Carambeí & dona de casa \\
\hline $\mathrm{AF}$ & $\bar{M}$ & 50 anos & $\begin{array}{l}\text { filho de pais } \\
\text { holandeses }\end{array}$ & $\begin{array}{c}\text { Telêmaco } \\
\text { Borba }\end{array}$ & contador \\
\hline $\mathrm{BD}$ & $\mathrm{M}$ & 50 anos & $\begin{array}{l}\text { filho de pais } \\
\text { holandeses }\end{array}$ & Carambeí & $\begin{array}{l}\text { guia de } \\
\text { museu }\end{array}$ \\
\hline WD & $\bar{M}$ & 47 anos & $\begin{array}{l}\text { filho de pais } \\
\text { holandeses }\end{array}$ & Carambei & agricultor \\
\hline RW & $\bar{M}$ & 46 anos & $\begin{array}{l}\text { filho de pais } \\
\text { holandeses }\end{array}$ & Carambeí & pecuarista \\
\hline RHB & $F$ & 44 anos & $\begin{array}{l}\text { filha de pais } \\
\text { holandeses }\end{array}$ & Carambeí & secretária \\
\hline IS & $F$ & 43 anos & $\begin{array}{l}\text { filha de pais } \\
\text { holandeses }\end{array}$ & Castrolanda & dona de casa \\
\hline WSGG & $F$ & 41 anos & $\begin{array}{l}\text { filha de mãe } \\
\text { indonésia e } \\
\text { pai holandēs }\end{array}$ & Carambeí & dona de casa \\
\hline AJWB & $F$ & 42 anos & $\begin{array}{l}\text { filha de pais } \\
\text { holandeses }\end{array}$ & Carambei & professora \\
\hline $\mathrm{CD}$ & $\mathrm{M}$ & 23 anos & $\begin{array}{l}\text { neto de avós } \\
\text { maternos e } \\
\text { paternos } \\
\text { holandeses }\end{array}$ & Carambei & estudante \\
\hline $\mathrm{FF}$ & $M$ & 22 anos & $\begin{array}{l}\text { neto de avós } \\
\text { paternos } \\
\text { holandeses }\end{array}$ & Carambei & estudante \\
\hline $\mathrm{DF}$ & $M$ & 24 anos & $\begin{array}{l}\text { neto de avós } \\
\text { paternos } \\
\text { holandeses }\end{array}$ & Carambeí & estudante \\
\hline
\end{tabular}




\begin{tabular}{|c|c|c|l|c|c|}
\hline MG & M & 21 anos & $\begin{array}{l}\text { neto de avós } \\
\text { maternos e } \\
\text { paternos } \\
\text { holandeses }\end{array}$ & Carambei & estudante \\
\hline GF & F & 22 anos & $\begin{array}{l}\text { neta de avós } \\
\text { paternos } \\
\text { holandeses }\end{array}$ & Carambei & estudante \\
\hline SSM & F & 21 anos & $\begin{array}{l}\text { filha de mãe } \\
\text { holandesa e } \\
\text { pai Carambeí } \\
\text { urasileiro" } \\
\text { (filho de pais } \\
\text { holandeses) }\end{array}$ & estudante \\
\hline MD & F & 20 anos & $\begin{array}{l}\text { neta de avós } \\
\text { maternos e } \\
\text { paternos } \\
\text { holandeses }\end{array}$ & Carambei & estudante \\
\hline FD & F & 21 anos & $\begin{array}{l}\text { neta de avós } \\
\text { maternos e } \\
\text { paternos } \\
\text { holandeses }\end{array}$ & Carambei & estudante \\
\hline
\end{tabular}

Quadro 1 - Perfil sociocultural dos informantes

a) Grupo 1M: informantes DG; HS; JG; BD. O Grupo $1 \mathrm{M}$ é o grupo dos idosos de Carambei. Têm entre 70 e 75 anos. O grupo é bilingue em holandês/português.

b) Grupo 1F: Informantes JLG; WGG; THS; WCGE. O Grupo $1 F$ é o grupo das idosas de Carambeí. Têm entre 70 e 75 anos. O grupo é bilingue em holandês/português.

c) Grupo 2M: Informantes AF; BD; WD; RW O Grupo $2 \mathrm{M}$ é o grupo dos que representam os adultos descendentes de holandeses de Carambeí e têm entre 45 e 50 anos. O grupo é bilingue em holandês/português.

d) Grupo 2F: Informantes RHB; IS; WSGG; AJWB. O Grupo $2 \mathrm{~F}$ é o grupo das que representam as mulheres adultas descendentes de holandeses de Carambei e têm entre 40 e 45 anos. O grupo é bilingue em holandês/ português.

e) Grupo 3M: Informantes CD; FF; DF; MG. O Grupo 3M é o grupo dos jovens descendentes de holandeses de Carambei, que têm entre 20 e 25 anos e estão concluin- 
do o ensino superior. Parte do grupo é somente bilingue incipiente em holandês/português.

f) Grupo 3F: Informantes GF; SSM; MD; FD. O Grupo $3 F$ é o grupo das jovens descendentes de holandeses de Carambei, que têm entre 20 e 25 anos. Parte do grupo também é somente bilingue incipiente em holandês/ português.

Dessa forma, mediante a comparação entre estas diferentes amostras, acredita-se ser possivel a generalização dos resultados obtidos.

\section{RESUltados E DisCUSSÃO}

O repertório linguístico da comunidade dos "holandeses" de Carambei/PR é constituído pelas línguas portuguesa e holandesa. Os usos linguísticos da comunidade, no que diz respeito a essas duas línguas, são descritos a seguir por grupos de informantes.

\section{Grupo $1 \mathbf{M}$}

Dentro da comunidade "holandesa" o grupo $1 \mathrm{M}$ corresponde ao grupo dos idosos do sexo masculino, descendentes dos primeiros imigrantes da comunidade, que, em geral, exerceram atividades ligadas à agricultura e estabeleceram pouco contato com o mundo externo à comunidade. O traço comum a esse grupo é a preferência pela língua holandesa ou, mesmo, o monolinguismo em holandês, além de um forte apego à cultura tradicional holandesa:

Talvez quando encontra um holandês, eu pergunto em holandês. (HS)

Muitos idosos são monolíngues em holandês, mas a maioria fala, pelo menos, um pouco de português, mesmo que com dificuldades: 
Os meus cunhados mais velhos prefiram o holandês em cima do portugués, porque aprenderam português como língua estrangeira. $O$ irmão mais velho dela, 89 anos, ele prefiram holandês e na igreja também. Português é sempre dificil pra ele. Ele fala português, mas ele prefiram holandês. (HS)

Os membros do grupo não revelam sentir dificuldades em falar, entender ou ler em holandês, somente em o escrever. E, segundo o grupo, essa dificuldade se deve ao pouco tempo que a escola dedicava ao ensino da escrita em holandês:

Eu praticamente nunca escrevi o holandés. Como executivo, viajava só no Brasil praticamente. E holandês eu aprendi. o que eu sabia de escrever, aprendi nas aulas de holandès aqui, dois anos. Só tivemos dois anos de holandès. Mas eu nunca cultivei isso. Nunca precisei. (DG)

\section{Grupo 1F}

Até 1970, a língua materna dos "holandeses" da colônia era o holandês, língua que era usada na vida doméstica das famílias (KOOY, 1978). Nessa época, o holandês era falado por todos os membros da família, mas vale destacar o papel das mulheres na garantia do aprendizado e da manutenção da língua. Eram as mulheres que ensinavam o idioma às crianças e, na maioria das familias em que ainda se fala holandês, são as mulheres que se preocupam em conservar a língua holandesa dentro dos lares:

Mas elas entendem o holandês porque a mãe sempre exige bastante delas também. né? (DG)

IO problema estál quando homem casa com mulher brasileira. né? Porque a màe é que fala com as crianças. Então ali é que se perde. Enquanto a mãe ta falando em holandês, você não perde. ( $H L V)$

Em geral, a mulher é a grande usuária da língua holandesa e só um pequeno número delas, as mais velhas, sobre- 
tudo, não fala português. Por essa razão, muitas mulheres com mais de sessenta anos consideram não ter um bom desempenho em português, pois têm um sotaque "muito carregado" nessa língua.

Algumas dessas idosas manifestam um conhecimento passivo do português, pelo contato com os filhos adultos, que discutem negócios diante delas e também pelo contato com os netos escolarizados:

Minha mãe entende um pouco de português; ela tenta ajudar os netos porque ela tem trinta e poucos netos. Muitos netos não sabe falar uma palaura em holandès, né? Mas então ela consegue conversar um pouquinho em portuguẽs, mas bem o básico mesmo, né? Bem pouco. (BD 2M)

Em termos concretos, as idosas têm bastante ou alguma dificuldade em falar português. No entanto, apesar de suas dificuldades, algumas demonstram que têm preocupação em integrar-se ao país (por meio da aprendizagem da lingua portuguesa) e fazem criticas aos que não se esforçam para deixar a condição de monolíngues:

Mas eu vejo o meu irmão e minha cunhada que já tá quantos anos aqui no Brasil, né? Eu penso: como vieram? Icomo falam mal!] Dai eu acho: isso não pode! Os mais antigos eu entendo ainda [que só falem holandês], porque a comunidade era tāo pequena. Todo mundo só falava holandês, nāo precisava do português. Hoje, nāo. (WGG)

\section{Grupo 2M}

Quanto ao grupo dos homens adultos, a maioria é bilíngue, ou seja, fala a língua portuguesa e a língua holandesa, reservando esta última para as relações com familiares mais idosos: 
[Falo holandês] só com os mais idosos. Meu nivel [idade] pra baixo só em portugués. Só com os mais idosos. Mas os mais idosos, a maioria começa a conversar em holandès, por eles saberem que você fala. Entāo eles começam com você, a opção deles número um é o holandès. Então eles vé que comigo dá pra falar, eles começam em holandês. (AF)

Hoje em dia se eu falo com a minha mãe é só em holandês também. (BD 2M)

No entanto, muitos homens afirmam que a comunicação em holandês é muito difícil, ao passo que "falar português é fácil" A principal razão alegada é a de que se fala muito mais português, em termos de frequência, do que holandês:

É muito dificil falar em holandês. Dificil. Portuguès é muito mais fácil. Português se fala com muito mais frequência. Então [se você] vai conversar com alguém, fala em português. (RW)

Muitos elementos do grupo revelam que têm dificuldades em ler e escrever em holandês:

Eu já mandei carta em holandès pra Holanda. Eu nào entendo tudo o que eu leio também, mas é dificil. Esse tipo de coisa, o " $u$ " não se fala " $u$ " né? Essas coisas é bem complicado. Eles emendam palauras, né? E dá pra aumentar muito mais essa palavra, né? É uma palavra só e que se for traduzi é uma frase inteira. (BD 2M)

Agora, escrever é uma tristeza. (WD)

Em relação aos filhos, muitos revelam que decidiram não lhes ensinar a lingua holandesa ou para que estes não tivessem sotaque "de holandês" no português, ou porque saber holandês "não serve para nada": 
não serve pra nada, infelizmente, infelizmente. Pra ser bem profissional, pra que que serve holandès, hoje, nessa regiāo? Porque fora de Carambeí, tá em Ponta Grossa já nāo serve. $90 \%$ da comunidade aqui nāo fala holandès. Serve pra quê? Só pros avós. Satisfazer tua mãe. (AF)

Por outro lado, para o grupo, a aprendizagem da lingua portuguesa sempre esteve ligada à questão de convivência com o mundo externo à comunidade. Dessa forma, para os homens dessa comunidade, falar a lingua portuguesa é uma das maneiras de proteger a família de possiveis perseguições e discriminações.

\section{Grupo 2F}

O bilinguismo português/holandês é tão frequente no grupo $2 \mathrm{~F}$ quanto no $2 \mathrm{M}$. Da mesma forma, no que diz respeito à transmissão da língua holandesa para os filhos, a grande maioria das mulheres optou por não o fazer, especialmente para que estes não tivessem sotaque "de holandês" no português:

Eu tenho um sotaque, eu sei que tenho bastante sotaque, mas é que eu fiquei muito tempo sozinha com meus pais, eu sou assim temporão, né? O meu é bem acentuado. Mas hoje eu penso: "puxa vida, lquel burra" O meu marido também fala holandês, então nós dois podiamos ter ensinado ela la filha a falar holandês]. Mas o cachorro é bilingue. Porque nāo tem problema se ele tiver sotaque. né? (IS)

Assim como os homens, as mulheres também reservam o uso da língua holandesa para as relações com familiares mais idosos:

É. se for um holandês mais velho. uma pessoa de geraçāo mais... Exato, ai, sim, a gente fala holandês. (AJWB) 
É que, na verdade, estes sāo mais velhos, eles tèm tendência pra falar em holandês. Se eles começam falar em holandès, eu respondo em holandês. (AJWB)

Ela começa falar em holandês com você, você fala o holandês de volta. (RHB)

Assim como os membros do grupo anterior, as mulheres também acham que escrever em holandês é muito difícil:

A gente se bate pra escrever. Eu me bato pra escrever uma carta lá pra tia. lá. Fica com o dicionário, né? Dai você vê, porque nào sabe se é com dois $k$. com dois $l$. com dois b. Lá tem muito disso aí, né? Mas eu já faço assim pra eu saber também, né? Como é que é, né? (IS)

\section{Grupo 3M}

Quanto ao grupo dos jovens "holandeses" do sexo masculino, todos frequentam a escola e sāo fluentes em português. Além disso, muitos se envergonham de ser identificados como "holandeses" pela associação que se faz entre ser imigrante holandês e ser "caipira":

Essa vergonha existe, [de] ser chamado de holandês (FF).

Em geral, os jovens "holandeses" do grupo sāo monolingues em português, muitos dos quais podem ser incluídos na categoria de bilingues incipientes:

O mais velho falava bem o holandès e a mais nova já tem muitas dificuldades. Ela fala, mas ela traduz do portuguẽs pro holandès. Viajou comigo para Holanda e ela nāo quis que eu ajudasse ela. "Eu falo holandês, nāo tem problema" E até que ela se mexeu bem. (HS)

Os jovens "holandeses" do grupo se mostram receptivos a tudo o que diz respeito à Igreja Reformada. Nesse sentido, con- 
sidere-se a assumida preferência dos jovens pelos cultos proferidos (em português) pelo pastor holandês. Praticamente todos vivem segundo os preceitos da igreja, mesmo que isso, em alguns casos, pareça bastante antiquado (KOOY, 1978):

Os jovens, por realizarem estudos fora da colonia, faziam contatos com os costumes e os pensamentos brasileiros, de fato bem diferentes do que os da colonia e talvez por isso atraentes para a juventude. Crescia uma geração cuja língua materna não era mais a holandesa, mesmo que a maioria ainda falasse este idioma. Mesmo assim, a influência do pastor Witzier era bem grande sobre os jovens. Quando ele uma vez proferiu as suas objeçōes contra o baile do chopp organizado pela associação dos funcionários da Cooperativa, no ginásio de esportes, nenhum dos jovens da igreja foi a esse baile. (KOOY, 1986, p. 251)

Como se afirmou, os jovens do grupo são monolíngues em português (ou bilingues incipientes em português/holandês), mas o que caracteriza o seu comportamento é o prazer de falar português. De modo concreto, o português predomina nas relaçōes sociais desses jovens. Quando o jovem sabe holandês, geralmente esta língua ocupa um lugar secundário nos seus usos linguísticos. Os jovens se consideram brasileiros, não se assumindo como "holandeses" Daí, a prática de privilegiar o uso da língua portuguesa. Em resumo, os jovens "holandeses" (mesmo os que são bilingues em português e holandês) caracterizam-se pelo uso preferencial do português:

Eles los filhos/ dizem: pra que que eu tenho que aprender la falar holandès]? (WSGG)

\section{Grupo 3F}

O grupo das jovens "holandesas" de Carambei também é fluente em português e somente uma parte é bilingue incipiente em português/holandês: 
Se você for ver, tem bem pouca menina assim da minha idade que entende holandês. Até falava quando era pequena. mas hoje não fala mais nada. (SSM)

Diferentemente dos rapazes, que manifestam uma atitude de rejeição em relação às tradições culturais holandesas, as jovens "holandesas" nutrem um carinho especial por aquela que é a lingua dos seus antepassados:

Acho tão bonito ver minha mãe falando com minha vó lem holandês]. Às vezes eu até entendo uma coisa ou outra. (GF)

As moças também se mostram receptivas a tudo o que diz respeito à Igreja Reformada, pois preferem os cultos proferidos (em português) pelo pastor holandès e vivem segundo os preceitos da igreja.

Assim como no caso do grupo anterior, o que caracteriza o comportamento linguístico das moças "holandesas" é o prazer de falar português e o predomínio dessa língua nas relações sociais que esses jovens mantêm entre si. Mesmo quando a jovem fala holandês "bem" esta lingua ocupa um lugar secundário nos seus usos linguísticos. Talvez porque elas se assumam como brasileiras e não como "holandesas" privilegiar o uso da língua portuguesa é uma prática comum do grupo.

O quadro a seguir sumariza as discussões do artigo. 


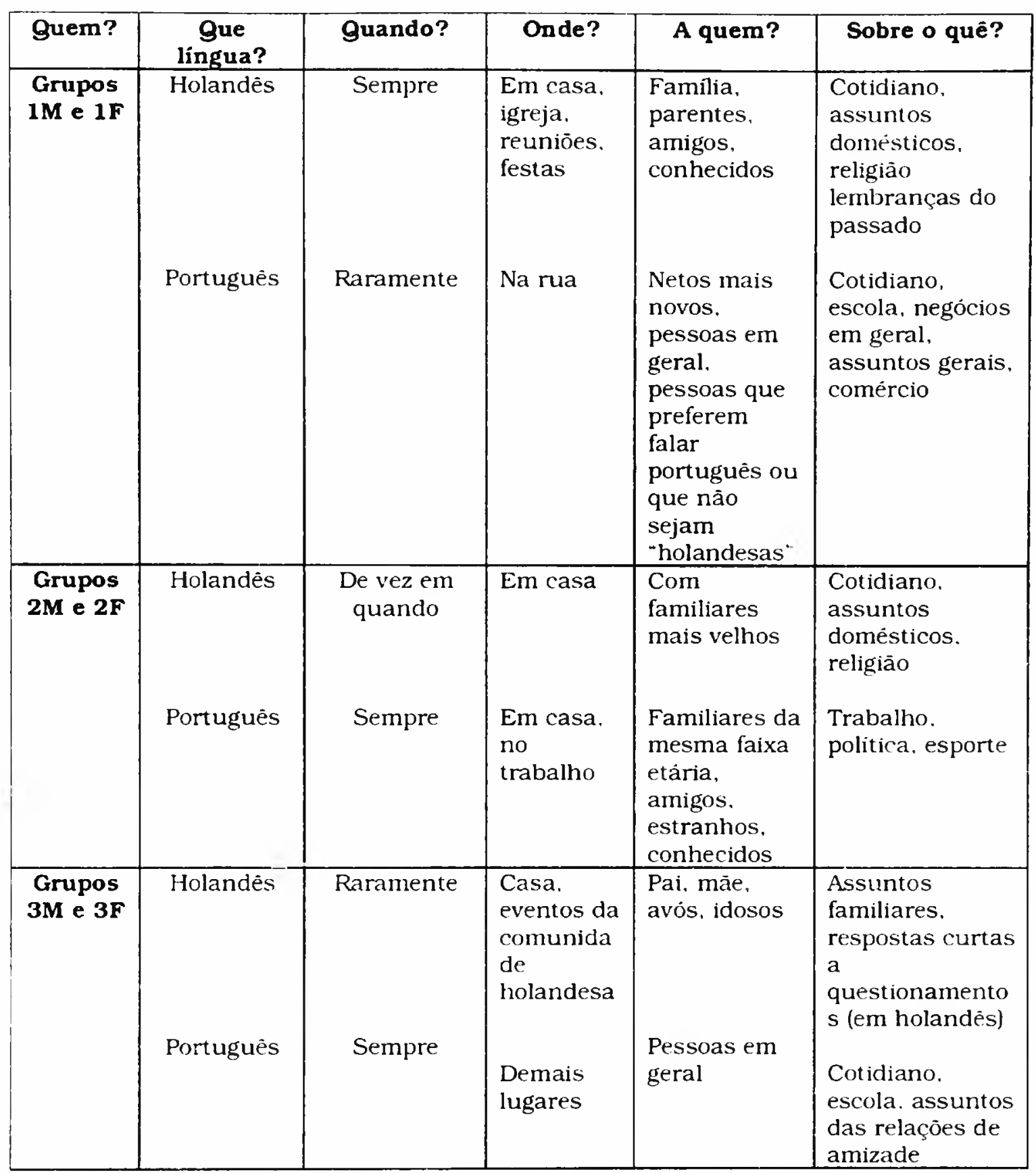

Guadro 2 - Usos linguísticos da comunidade holandesa de Carambeí/PR Fonte: Dados da pesquisa da autora.

\section{CONSIDERAÇŌES FINAIS}

Neste trabalho, nos propusemos a analisar mais detidamente a comunidade de fala holandesa da colônia de Carambei, com o objetivo de estabelecer os usos funcionais das línguas portuguesa e holandesa naquela localidade. No 
que diz respeito a essa questão que nos propusemos responder, concluímos que o Grupo $1 \mathrm{M}$ tem preferência pela língua holandesa, além de ter um forte apego a sua cultura tradicional. Em relação à língua portuguesa, o grupo tem dificuldade em falar português, mas demonstra que tem preocupação em integrar-se ao país (por meio da aprendizagem da lingua portuguesa) e faz críticas aos que não se esforçam para deixar a condição de monolíngues. Já o Grupo $1 F$ é composto pelas grandes usuárias da língua holandesa. Por essa razão, muitas mulheres com mais de sessenta anos consideram não ter um bom desempenho em português, pois têm um sotaque "muito carregado" nessa língua. O Grupo 2M é bilíngue, ou seja, fala a língua portuguesa e a língua holandesa, reservando essa última para as relações com familiares mais idosos. No entanto, em relação aos filhos, muitos revelam que decidiram não ensinar a lingua holandesa a eles ou para que estes não tivessem sotaque "de holandês" no português, ou porque saber holandês "não serve para nada" Por outro lado, falar a língua portuguesa é percebido como uma maneira de proteger a familia de possiveis perseguições e discriminações. $O$ Grupo 2F também é bilíngue em português/holandês e, assim como o grupo anterior, no que diz respeito à transmissão da lingua holandesa para os filhos, optou por não o fazer, especialmente para que estes não tivessem sotaque "de holandês" no português. Enfim, os Grupos 3M e 3F dos jovens holandeses, são monolingues em português, admitem que preferem falar português e muitos podem ser incluidos na categoria de bilíngues incipientes em holandês.

\section{BiBLIOGRAFIA:}

ARNOULD, Eric J.; WALLENDORF. Melanie. Market-oriented ethnography: interpretation building and marketing strategy formulation. Journal of Marketing Research, v. 31, n. 4, p. 484-504, Nov. 1994.

HYMES, Dell H. Language in culture and society: a reader in linguistics and anthropology. New York: Harper and Row, 1964. 
KOOY, Hendrick Adrianus. Carambei 75 anos (191 1 1986). Carambeí: Ed. do Autor, 1978.

SAVILLE-TROIKE, Muriel. The ethnography of communication, an introduction. 2 ed. Oxford, Blackwell, 1989.

ABSTRACT: Carambeí, a small town in Paraná, is Brazil's first Dutch settlement, founded in 1911. Considering that Carambei Township is fairly complex, both cultural and linguistically, this study intends to do a survey of the functional use of Portuguese and Dutch languages. As far as the first question is concerned, we concluded that Groups $1 \mathrm{M}$ and $1 \mathrm{~F}$ prefer Dutch; Groups $2 \mathrm{M}$ and $2 \mathrm{~F}$ are bilingual in Portuguese and Dutch; Groups $3 \mathrm{M}$ and $3 \mathrm{~F}$ are monolingual in Portuguese.

Keywords: Portuguese; Dutch; Linguistics varieties; Social uses 